\title{
Reversed Hemisoleus Flap for Traumatic Wound Coverage in the Distal Third of the Leg
}

\author{
AHMED A. FISAL, M.Sc.; LOTFY M. YOUNES, M.D.; MUHAMMAD A. QUOLQUELA, M.D. and \\ MUHAMMAD A. ROMEIH, M.D.
}

The Department of Orthopaedic Surgery, Faculty of Medicine, Tanta University

\begin{abstract}
Background: Reconstruction of soft tissue defects of the distal third leg are common challenging therapeutic problems with significant long-term morbidity. Treatment options include cross leg flaps, local flaps (as muscle flaps and fasciocutaneous flaps) and the free vascularized flaps.

Aim of Study: The aim of this study is to evaluate the clinical outcome of reversed hemisoleus muscle flap in coverage of traumatic soft tissue defects in the distal third of the leg.

Patients and Methods: In this prospective study, we present 21 patients with traumatic soft tissue defects in the distal third leg with exposure of bone, tendons and neurovascular structures, managed by reversed medial hemisoleus muscle flap. Clinical and radiological data were analyzed.

Results: The outcome of the flap surgery was evaluated after at least 6 months follow-up on the basis of flap survival, graft intake, functional gain and donor site morbidity [1] Clinical results were graded as excellent, good, fair as follows: 13 showed excellent results $(61.9 \%), 7$ showed good survival $(33.3 \%)$ and 1 flap was graded as fair $(4.8 \%)$ with no poor results. The excellent and good results were considered as satisfactory results, while the unsatisfactory included the fair and the poor results. Accordingly, satisfactory results were found in 20 patients $(95.2 \%)$, and the unsatisfactory results were found in 1 patient $(4.8 \%)$ with reliable soft-tissue coverage and complete wound healing in all patients.
\end{abstract}

Conclusion: This study shows that reversed medial hemisoleus muscle flap is a reliable reconstructive option for traumatic soft tissue defects on the medial side of the distal tibia in selected cases.

Key Words: Distal 1/3 tibia - Soleus - Muscle flap.

\section{Introduction}

ONE of the most challenging and common areas in reconstruction facing orthopaedic surgeons is the closure of soft tissue defects in the lower extremity. By far the most common etiology for

Correspondence to: Dr. Ahmed A. Fisal, The Department of Orthopaedic Surgery, Faculty of Medicine, Tanta University defects requiring reconstruction is trauma. The most common site for reconstruction of the leg is the distal leg. This area has limited soft tissue for protection of vital structures, tightness, and limited mobility of the skin with by poor circulation. Thus chronic infection following Achilles tendon rupture or trauma surgery often occur leading to exposed bone, tendons, vessels or nerves. Impaired vascular flow also inhibits the healing of small defects which may ultimately result in extensive defects which require free flap coverage $[1,2]$.

Regarding trauma being the most common cause, severe injuries of the lower extremities such as Gustillo type III-B injuries of the distal third leg caused by road traffic accidents, outdoor falls $\&$ sports happen more often than before. They have high incidence of infection \& non-union. They are usually accompanied by extensive soft tissue damage \& leg defects ranging from small to large ones, severe comminuted fractures or bone defects \& even vascular injuries adding another difficulty to the limb reconstruction $[4,5]$.

Regarding soft-tissue defects, the optimal timing of the operation, the most suitable type of tissue, and the consideration between a local or free approach still remains under discussion. However, the use of free tissue transfer for soft-tissue coverage of the distal third leg has been the method of choice for this reconstruction. Other options available for reconstruction of such defects. Usually including local muscle flap, fasciocutaneous flap and cross-leg flap $[7,8]$.

The decreasing trend of the usage of microvascular flaps in the acute lower limb trauma is also due to fairly high incidence of failure and the cost of the treatment with significant donor site morbidity. The injured limbs in failed free flap surgeries 
are even more difficult to salvage. These factors justify the usage for free flaps only when the local or regional flaps are not feasible either because of the size or extensive local tissue trauma [9]

The soleus muscle is frequently used as a local muscle flap for the reconstruction of defects of the middle third of the leg, based on its major pedicle. However, the viable use of the hemisoleus muscle in a reverse manner, based on its secondary distal pedicles, has been described by several authors for the reconstruction of defects of the lower third of the leg as an alternative to the microsurgical flaps [10-12]

The aim of this study is to evaluate the results of reversed hemisoleus muscle flap in coverage of traumatic soft tissue defects in the distal third of the leg.

\section{Patients and Methods}

\section{A- Patients:}

This study is prospective study included 21 patients (18 males, 3 females and their ages range
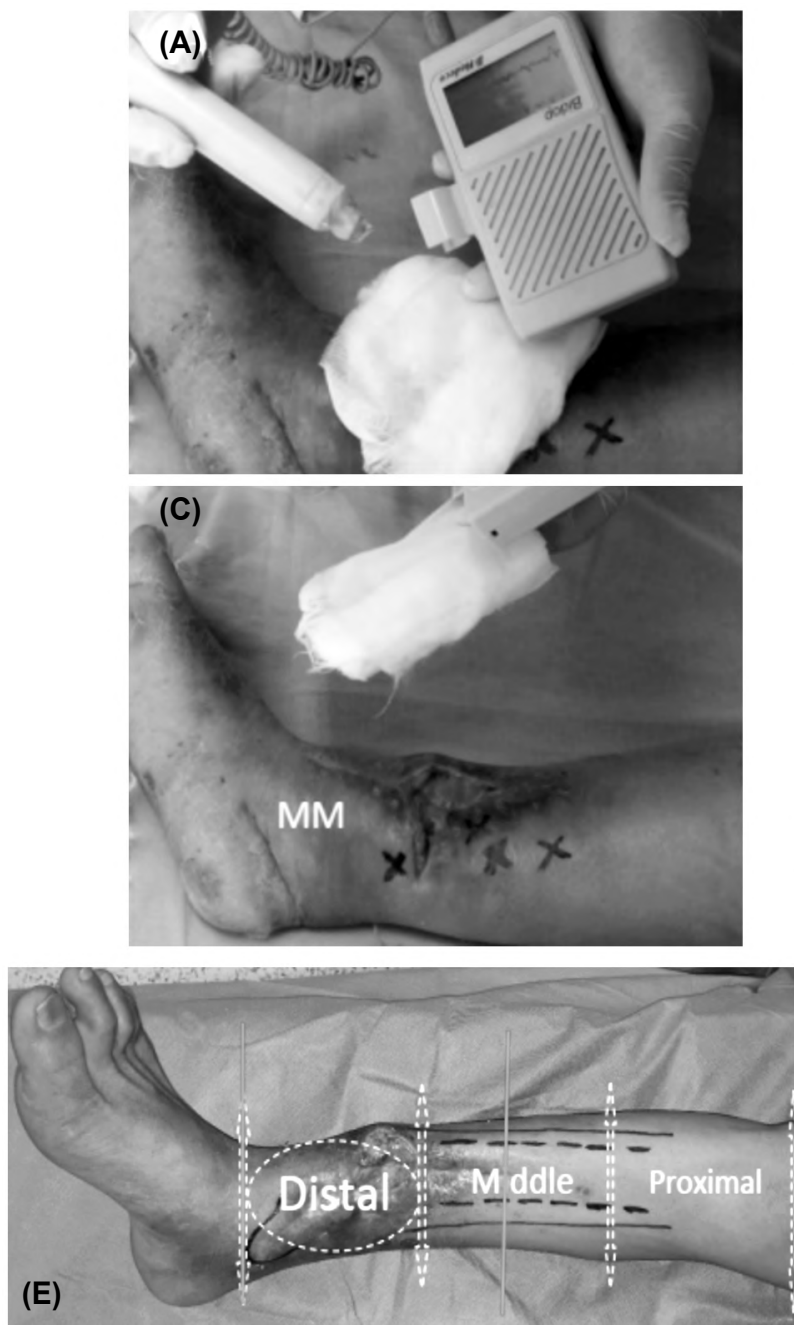

from 15 years to 65 years with an average of 33 ) with traumatic soft tissue defects in the medial side of the distal third leg were treated with reversed medial hemisoleus muscle flap in the Orthopedics and Traumatology Department of Tanta University Hospital between October 2017 and October 2018. The location of the soft-tissue defect was on the right side in 11 patients and on the left side in 10 patients.

\section{Clinical examination:}

General examination: Blood pressure, pulse, temperature, respiration and other body systems. Associated injuries was documented.

Local examination: Full local examination including soft tissue evaluation and neurovascular assessment. The extent, dimensions of the defects and exposure of bone or tendons. Photographs were taken. Routine hand held Doppler ultrasound examination Fig. (1) was done in all cases to confirm the patency of distal perforators prior to surgery. Plain X-ray (AP and Lateral views) to rule out associated fractures.
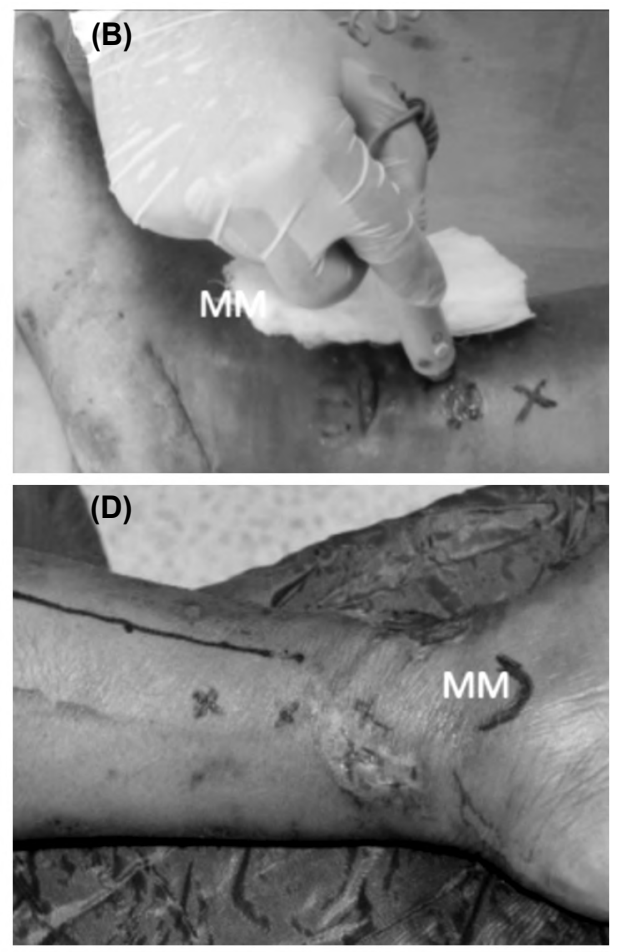

Fig. (1): Clinical photos of Doppler examination. (A): Hand held Doppler. (B): Searching for the distal perforators at 5,10 and $15 \mathrm{~cm}$ from medial malleolus. (C,D) Location of distal perforators with a medial distal third leg defect (x). (E) Showing the defect (between 2 red lines) after dividing the leg into equal thirds (white arrows) from the tip of (MM) to the level of the knee joint. 
Computed Tomography Angiogram (CTA) was performed before surgery in 6 of our patients (4 diabetics and 2 heavy smokers) who had questionable distal perforators on hand held Doppler examination to assess the permeability of the popliteal vessels, its branches and the major distal perforators from the Posterior Tibial Artery (PTA) to the distal portion of the medial soleus muscle.

The inclusion criteria were patient with distal third leg defects $<80 \mathrm{~cm}^{2}$ that cannot be closed directly without tension provided patency of one or more of distal perforators located approximately at 5,10 and $15 \mathrm{~cm}$ proximal to Medial Malleolus (MM) confirmed by hand held Doppler examination and/or Computed Tomography Angiogram (CTA) prior definitive soft tissue coverage.

While, the main exclusion criteria were patients with extensive tissue loss $\left(>80 \mathrm{~cm}^{2}\right)$ or wounds at the pedicles site. Previous gastrocnemius or soleus resection in trauma or after tumor removal. Vascular injuries as (Gustilo Anderson type 3C open fracture tibia).

\section{B- Methods:}

Stabilization of the patients was done, tetanus prophylaxis, and broad-spectrum antibiotics were given in 19 cases who were presented immediately after trauma to our ER Department. Aggressive debridement of non viable tissue was done. Above knee back slap was applied in 19 patients ( 5 intact tibia and 14 tibial fractures) after the initial debridement. Preliminary external fixation in 1 patient for 3 weeks was done (unstable open fracture Gustilo IIIB with bone defect to avoid further soft tissue injury by the fracture fragments) before definitive skeletal stabilization and flap coverage. Debridement was repeated when tissue viability was uncertain every $48 \mathrm{hrs}$.

When the wound bed was clean, the flap was designed and performed as soon as possible, within the first 10 days following initial injury. The distally based hemisoleus flap was the primary management option for 15 patients $(71.4 \%)$ within 10 days. However, NPWT was applied for 2-3 weeks preoperatively for wound care in 6 patients when the flap was performed after 10 days. Timing of definitive soft tissue coverage ranged from ${ }^{1 \text { st }}$ day of trauma to 6 months after the initial trauma with a mean of 16 days.

Spinal anesthesia was used in 16 patients, general anesthesia in 4 patients and spinal epidural was used only in one patient. In case of associated fractures, stabilization of the bone was performed 1 st in supine position, then flap harvest position was chosen depending on the location of the defect either supine or semi-prone position.

A longitudinal skin incision was made under a tourniquet control about $2 \mathrm{~cm}$ medial to the posteromedial subcutaneous palpable border of the tibia and parallel to it. The length of the incision started proximally from the junction between the proximal $\&$ middle one thirds of the leg, and stopped distally $10 \mathrm{~cm}$ above the medial malleolus.

Caution was taken to identify and retract the greater saphenous vein as well as the saphenous nerve. Once these two structures were identified, dissection was carried down to the investing fascia of the superficial posterior compartment overlying the gastrocnemius muscle.

The soleus muscle was identified proximally deep to the gastrocnemius muscle. Blunt dissection was used to easily separate the more superficial medial gastrocnemius muscle belly from the medial soleus muscle belly, the plantaris runs in the plane between the two muscles. The plane between the two muscles is relatively avascular with the exception of some small perforators which were ligated.

By performing sharp dissection, the medial soleus was separated from its anterior tibial attachments. The muscle was then separated anteriorly from the Flexor Digitorum Longus (FDL). During this dissection, the posterior tibial neurovascular pedicle became visible and was protected between the soleus and (FDL).

The medial hemisoleus muscle flap transected just lateral to median raphe incorporating the raphe, leaving the lateral hemisoleus muscle in situ to preserve motor function.

During distal dissection, as many distal perforators as possible should be preserved while allowing an adequate arc of the flap turnover to cover the exposed tibia or hardware. The proximal part of the medial soleus was transected at the level of the proximal and middle thirds of the muscle.

The tourniquet was deflated and perfect hemostasis was done. Muscle flap viability was checked and non-viable fibers were debrided down to bleeding muscle fibers.

Multiple transverse incisions through the epimysium were done to increase the muscle surface area. 
The medial hemisoleus muscle was turned over or transposed into the defect without vessel kinking and inset with absorbable 3-0 vicryl half buried mattress sutures to the periphery of the defect to be overlapped by the undersurface of the normal skin. Muscle tunneling was avoided as this could jeopardize the vascularity of the flap. Direct donor site closure was done using 3-0 vicryl for subcutaneous and 3-0 proline or staples for the skin closure.

Delayed skin grafting was done in all cases to confirm flap survival before skin grafting. Vaseline impregnated gauze dressing with local antibiotic ointment were used to cover the muscle flap. A well-padded posterior plaster splint was applied with care to prevent any compression of the pedicle or the flap.

Average operative time of the cases from incision to skin closure ranged between 55 and 93 minutes for medial hemisoleus muscle harvesting, transposition and fixation to the defect with a mean of 73.6 minutes, and ranged from 15 to 23 minutes for delayed Split Thickness Skin Grafting (STSG) after 5-7 days with a mean of 18.8 minutes. On follow-up visits, which was on $2,4,6,8$, and 10 weeks then every other month after the discharge. All patients were followed for at least 6 months post-operatively.

\section{Case presentation:}

A 45 years old diabetic and smoker man sustained Gustilo type III B open fracture of the left distal both bones leg caused by a train fall Fig. (2A). He initially underwent debridement of the open tibial fracture wound. After further debridement, a $10 \times 7 \mathrm{~cm}$ tibial wound in the distal third of his leg, with an exposed tibial fracture site NPWT was applied for 3 weeks till optimizing his glycemic control preoperatively $(<200 \mathrm{mg} / \mathrm{dl})$.

Hand held Doppler examination and CTA confirmed the patency of the distal PTA perforators. The patient was operated 22 days following the initial injury by open reduction through the preexisting wound after extension and definitive internal fixation using plate and screws with iliac crest bone graft. The wound was covered with reversed medial hemisoleus muscle flap.

The muscle flap was skin grafted one week afterward following immediate debridement of a small distal necrotic portion) and advancement of the flap. The soft tissue and the fracture healed eventually Fig. (2B) with full mobilization and return to the pre-injury level of activity.
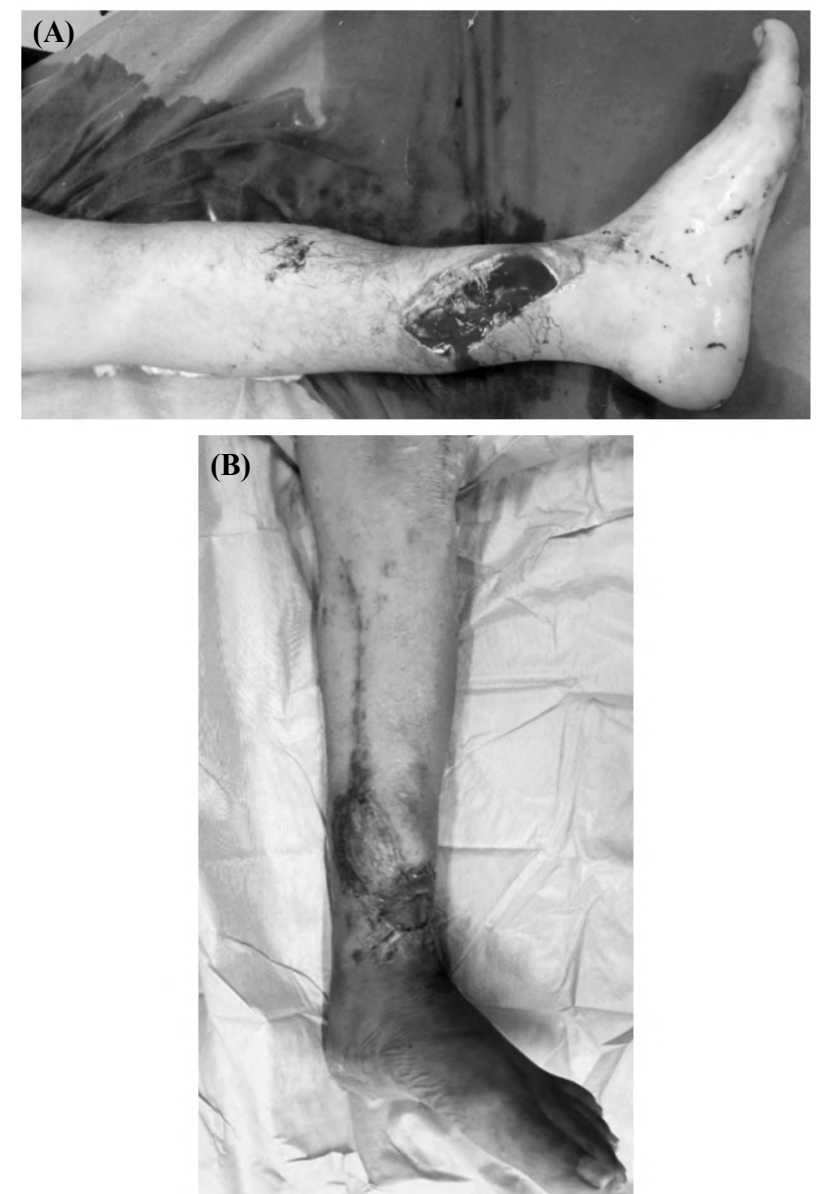

Fig. (2): (A): Showing the traumatized lower extremity on admission with the soft tissue defect over the distal third leg. (B): Complete wound healing with return to pre-injury level of activity.

\section{Results}

The outcome of the flap surgery was evaluated according to our modifications of Ahmad I et al., [28], 1 on the basis of flap survival and graft intake. A grading of excellent depicts no flap loss and survival of the skin grafted over the flap surface, good depicts where there is some loss of skin grafted over the flap or marginal loss of the flap $<20 \%$ (distal tip necrosis), fair depicts where there is partial flap loss $(>20 \%<50 \%)$ and poor depicts where complete loss of the flap or necrosis of more than $50 \%$ of the flap.

Of the 21 flaps and at the time of delayed skin grafting (5-7 days after the flap coverage) that was done in all cases to confirm the flap survival before grafting, 15 flaps $(71.4 \%)$ were fully viable (Table 1), 5 flaps (23.8\%) showed insignificant distal tip necrosis (defined as $<20 \%$ necrosis at the distal part of the flap 5 days after transposition) where debridement and advancement were done before skin grafting with complete healing of the wounds in the follow-up visits. 
Table (1): Grading of muscle flap survival and final outcome.

\begin{tabular}{llcccc}
\hline Flap viability & $\begin{array}{c}\text { Complete } \\
\text { viability }\end{array}$ & $\begin{array}{c}\text { Distal tip } \\
\text { necrosis }\end{array}$ & $\begin{array}{c}\text { Partial } \\
\text { loss }\end{array}$ & $\begin{array}{c}\text { Total } \\
\text { loss }\end{array}$ & $\begin{array}{c}\text { Total } \\
\text { cases }\end{array}$ \\
\hline $\begin{array}{l}\text { No. of patients } \\
\%\end{array}$ & 15 & 5 & 1 & 0 & 21 \\
Outcome & 71.4 & 23.8 & 4.8 & 0 & 100 \\
& Excellent & Good & Fair & Poor & \\
\multicolumn{4}{c}{ Satisfactory } & Unsatisfactory \\
\hline
\end{tabular}

We witnessed partial flap loss $(30 \%$ necrosis of the flap) in 1 flap (4.8\%) managed with debridement, NPWT and later a skin graft was applied after a course of dressing changes again with complete wound coverage. No cases of total flap necrosis. 13 showed excellent results, 7 showed good survival and 1 flap was graded as fair with no poor results. Twenty cases showed satisfactory outcome with 1 unsatisfactory regarding flap viability Fig. (3) and (Table 2).

Follow-up period ranged from 6 to 9 months with a mean of 6.6 months. The patients were followed-up until the flap provided reliable softtissue coverage and complete wound healing in all patients.

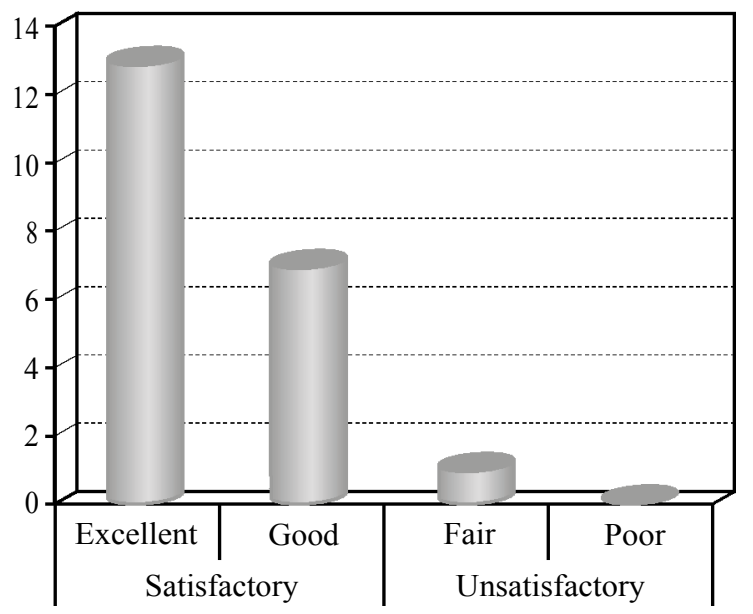

Fig. (3): Satisfactory and unsatisfactory results.

Table (2): Satisfactory and unsatisfactory results.

\begin{tabular}{|c|c|c|c|c|c|c|c|c|}
\hline \multicolumn{5}{|c|}{ Satisfactory } & \multicolumn{3}{|c|}{ Unsatisfactory } & \multirow{2}{*}{ Total } \\
\hline Excellent & & ood & & tal & Fair & Poor & Total & \\
\hline No. $\%$ & No. & $\%$ & No. & $\%$ & No. $\%$ & No. $\%$ & No. $\%$ & \\
\hline 61.9 & 7 & 33.3 & 20 & 95.2 & 14.8 & 0 & 14.8 & $21 \quad 100$ \\
\hline
\end{tabular}

Table (3): Final results.

\begin{tabular}{|c|c|c|c|c|c|c|c|c|c|c|}
\hline $\begin{array}{l}\text { Age } \\
\text { (ys)/ } \\
\text { sex }\end{array}$ & Smoking & $\begin{array}{c}\text { Medical } \\
\mathrm{Hx}\end{array}$ & $\begin{array}{l}\text { Days } \\
\text { before } \\
\text { surger }\end{array}$ & $\begin{array}{c}\text { Site } \\
\text { of } \\
\text { defect }\end{array}$ & $\begin{array}{l}\text { Siz of } \\
\text { defect } \\
(\mathrm{cm})\end{array}$ & $\begin{array}{l}\text { Fx \& method } \\
\text { of Fix }\end{array}$ & Copmlications & Secondary intevention & $\begin{array}{c}\text { Flap } \\
\text { outcome }\end{array}$ & $\begin{array}{l}\text { Bony } \\
\text { outcome }\end{array}$ \\
\hline $22 / \mathrm{M}$ & NO & NO & 1 & Junction & $9 \times 5$ & Fx/ILNT & NO & Non & Excellent & Healed \\
\hline $36 / \mathrm{M}$ & $\mathrm{S}$ & NO & 8 & Dista $1 / 3$ & $10 \times 5$ & Fx/ILNT & Partial graft loss & Appropriate deressing & Good & Healed \\
\hline $32 / \mathrm{M}$ & NO & HTN & 1 & Dista $1 / 3$ & $6 \times 3$ & Tension band MM & $\mathrm{NO}$ & Non & Excellent & Healed \\
\hline $55 / \mathrm{F}$ & NO & $\mathrm{NO}$ & 5 & Junction & $8 \times 6$ & Fx/ILNT & NO & Non & Excellent & Healed \\
\hline 29/M & $\mathrm{S}$ & NO & 4 & Dista $1 / 3$ & $9 \times 7$ & Fx/ILNT & Distal tip necrosis & Debrid. \& advancement & Good & Healed \\
\hline $15 / \mathrm{M}$ & NO & $\mathrm{NO}$ & 8 & Dista $1 / 3$ & $6 \times 4$ & NO & NO & Non & Excellent & - \\
\hline $65 / \mathrm{F}$ & NO & DM & 16 & Dista $1 / 3$ & $10 \times 7$ & Fx/Nancy & Distal tip necrosis & Debrid. \& advancement & Good & Healed \\
\hline $33 / \mathrm{M}$ & NO & NO & 3 & Junction & $10 \times 6$ & $\mathrm{Fx} / \mathrm{ILNT}$ & NO & Non & Excellent & Healed \\
\hline 49/M & $\mathrm{S}$ & DM & 18 & Dista $1 / 3$ & $13 \times 6$ & Fx/ILNT & Partial flap loss & Debrid., NPWT \& STSG & Fair & Healed \\
\hline $25 / \mathrm{M}$ & NO & NO & 6 & Junction & $10 \times 5$ & Fx/ILNT & NO & Non & Excellent & Healed \\
\hline $18 / \mathrm{M}$ & $\mathrm{S}$ & NO & 5 & Dista $1 / 3$ & $8 \times 5$ & NO & NO & Non & Excellent & - \\
\hline $45 / \mathrm{M}$ & S & $\mathrm{DM}$ & 22 & Dista $1 / 3$ & $10 \times 7$ & ExFix/ORIF + BG & Distal tip necrosis & Debrid. \& advancement & Dood & Healed \\
\hline $35 / \mathrm{M}$ & NO & NO & 4 & Junction & $7 \times 5$ & NO & NO & Non & Excellent & - \\
\hline $28 / \mathrm{M}$ & NO & HTN & 7 & Junction & $8 \times 7$ & Fx/ILNT & NO & Non & Excellent & Healed \\
\hline $21 / \mathrm{F}$ & NO & $\mathrm{NO}$ & 9 & Junction & $11 \times 5$ & Fx/ILNT & $\mathrm{NO}$ & Non & Excellent & Healed \\
\hline $47 / \mathrm{M}$ & $\mathrm{S}$ & DM & 12 & Dista $1 / 3$ & $11 \times 6$ & Fx/ILNT & Distal tip necrosis & Debrid. \& advancement & Good & Healed \\
\hline 19/M & NO & NO & 5 & Junction & $9 \times 5$ & NO & NO & Non & Excellent & - \\
\hline $29 / \mathrm{M}$ & NO & NO & 1 & Dista $1 / 3$ & $9 \times 6$ & Fx/ILNT & NO & Non & Excellent & Healed \\
\hline 23/M & $\mathrm{S}$ & NO & 13 & Dista $1 / 3$ & $8 \times 6$ & NO & Partial graft loss & Appropriate deressing & Good & - \\
\hline $31 / \mathrm{M}$ & NO & NO & 8 & Junction & $9 \times 4$ & Fx/ILNT & NO & Non & Excellent & Healed \\
\hline 40/M & $\mathrm{S}$ & NO & 180 & Junction & $9 \times 6$ & ILNT + BG & Distal tip necrosis & Debrid. \& advancement & Good & Healed \\
\hline
\end{tabular}

\section{Discussion}

The detailed anatomical knowledge of soleus vascularity assists the application of the hemisoleus muscle as a flap in a rational and predictable reversed manner to cover the soft tissue defects of the distal leg that was designed and suggested by Tobin [13] in 1985.
Over the past 20 years, $\mathrm{Pu}[\mathbf{1 4 , 1 5}]$ has refined techniques in flap dissection and successfully used this flap for soft-tissue reconstruction with good to excellent outcome and minimal morbidity.

The purpose of our study was to report our results in treatment of traumatic soft tissue defects in the distal third leg with the reversed medial 
hemisoleus muscle flap, with emphasis on understanding blood supply to the flap and refinements in flap dissection. The indications and limitations of the flap along with management of flap complications such as distal flap necrosis are also discussed.

The mean age in our study was 33 years old (15 to 65) conforming with the mean age incidence reported in literature by Rabbani et al., [16] with a mean of 30 (12 to 65), Fayman et al., [17] with a mean of 32 (22 to 57), with the mean age of 32 (14 to 65), Pu [14] with a mean age of 35 (12-52), Kauffman et al., [12] with a mean of 38 (18 to 61). However, others reported higher mean age as Sayed [18] with a mean of 46 (28 to 72),Schierle et al., [8] with a mean of 59 (34 to 78), Houdek et al., [19]with a mean of 67 (46 to 81).

Our study showed male predominance involving 18 males and 3 females which reflects that males have higher level of activity and more susceptibility to trauma and this scenario was found to be predominant in literature. However, Houdek et al., [19] reported equal gender distribution in his study.

In this study, 16 defects were associated with tibial fractures, while the remaining 5 defects had no bony fractures, 4 with exposed intact tibia after degloving injuries and 1 defect with exposed Achilles tendon after dehisced repair site. Based on previously mentioned evaluation method, 20 flaps healed satisfactorily (13 excellent and 7 good) with no further intervention and 1 flap with fair outcome that required minimal $2^{\mathrm{y}}$ procedure for complete healing. Eventually, all flaps healed with a good functional outcome, complete closure of the exposed structures, no dehiscence of the reconstructed area, no infection, complete fractures healing, a progressive return to ambulation at routine followup visits with good planter and dorsi-flexion power, and no recurrence of the wound after 6.6 (range 6 to 9) months.

Regarding the flap survival, we experienced $23.8 \%$ distal tip necrosis (5 of our 21 patients), which was insignificant and treated with debridement and flap advancement in the same setting of delayed skin grafting. 1 case of partial flap necrosis (30\% necrosis of the flap) that required debridement and later on a STSG. No total flap loss was observed in our study.

Our results were nearly similar to $\mathrm{Pu}$ [14] who reported 25\% distal flap necrosis (in 2 patients) after reversed medial hemisoleus muscle flap for reconstruction of an open tibial wound ranging 9-
$60 \mathrm{~cm}^{2}$ in the lower third of the leg in a series included 10 patients.

In a study by Rabbani et al., [16] with defects sizes $<50 \mathrm{~cm}^{2}$, Primary healing was achieved in 33 cases $(86.8 \%)$. There was partial necrosis of flap without dehiscence in 3 cases $(8.1 \%)$ and partial necrosis with dehiscence in 1 case $(2.7 \%)$. All three cases of partial necrosis without dehiscence healed by secondary intension satisfactorily. There was no total loss of the flap in the study. All patients, ultimately, achieved wound coverage with good cosmesis due to lesser bulk of the muscle. Patients with history of poly trauma, high velocity injuries and diabetes mellitus were excluded.

Our results were inferior to those encountered in a series by Schierle et al., [8], the outcomes of 17 patients undergoing distally based medial hemisoleus flaps were successful in using this flap for soft tissue coverage measuring $<50 \mathrm{~cm}^{2}$ in the distal leg in 16 patients with the only complication involving a small area of distal tip necrosis present in 1 patient $(6 \%)$.

Houdek et al., [19] achieved successful coverage in 9 of 10 patients withreversed medial hemisoleus flaps for coverage of distal third leg wounds with soft tissue defect ranging $8-45 \mathrm{~cm}^{2}$, with distal tip necrosis occurring in 1 patient $(10 \%)$.

Our relatively higher incidence of distal tip of flap necrosis than Schierle et al., [8] and Houdek et al., [19] could be attributed to higher risk factors in the 5 cases of distal tip necrosis, 4 of them being smokers, 3 of them being diabetics and all of them with defects $>60 \mathrm{~cm}^{2}$ (up to $78 \mathrm{~cm}^{2}$ ) and our greater number of cases (21 cases). Besides, the previous studies didn't comment on smoking and DM as major risk factors in flap survival. Schierle et al., [8] described the benefits of adhering to principles of angiosomes when designing a muscle flap. By capturing one full angiosome in their flap design, the patients in the study had successful outcomes with a healed wound.

Regarding graft intake, 2 flaps in our study (9.5\%), also being smokers, showed partial graft loss $(<50 \%$ graft loss $)$ which healed satisfactorily by dressing. Our results was higher than Houdek et al., [19] who did immediate skin grafting in the same flap inset and experienced graft loss in 4 flaps (19\%) requiring repeated skin grafting. $\mathrm{Pu}$ [14] and Schierle et al., [8] experienced 1 case of partial skin graft loss $(6 \%)$ treated with regrafting.

Regarding the site of the defects, all the defects managed in our series were located on the medial 
side of the distal third of the leg. This reflects that the medial defects are more common than the lateral ones in agreement with the literature, owing to the limited soft tissue for protection and coverage of vital structures including bone, tendons, and neurovascular structure, tightness, and limited mobility of the skin over the tibia with poor circulation [20-24].

Though Karbalaeikhani et al., [25] could not prove the ability of the reverse hemisoleus flap to cover soft tissue defects in the distal third of the leg, he believed that free flaps must not be viewed as the first choice. Free-flap coverage has many disadvantages and is not possible at times, so many surgeons still prefer local flaps, and in case of their failure the free flap will be a good choice [26,27]

To compare our findings with those in literature regarding the effect of time lag on successful outcome of medial hemisoleus flap, Houdek et al., [19] reported the mean time between the initial injury and the flap coverage was 35 days (range 2-248) with no mention of its influence on the outcome. Other studies of medial hemisoleus flap didn't report the period of time from initial trauma till flap coverage.

In a study done by Ahmad I et al., [28] on 42 patients with defects at lower third of leg, covered by distally based posterior tibial artery perforator flap. All the flaps survived and were taken up well except for 1 patient $(2.4 \%)$ who experienced complete flap loss. Minor complications were noted in four other patients $(9.5 \%)$. 1 patient developed superficial epidermolysis, 1 developed post-operative venous congestion, which subsided within 3 days by conservative means, and in 2 patients, partial loss of the skin graft occurred at the donor site. The patient who developed complete flap loss required a cross-leg flap.

We found that our results were comparable with the previous study as a local flap with no need for microvascular anastomosis, but again with no complete flap failure. An advantage of using fasciocutaneous perforator flaps over our muscle flap is that the lost tissue is replaced with like, using only the elements that are required for wound coverage, namely, the skin and subcutaneous tissue. This allows for precision in contour and color match. However, compared with fasicocutaneous flaps, the hemisoleus as a muscle flap provides a better supply for improved fracture healing when orthopedic trauma is present, treatment of infection and an obliteration effect because of their bulky tissue $[8,27,29]$.

\section{Conclusion:}

Reversed medial hemisoleus muscle flap represents a good alternative to the free flaps in the setting of traumatic injuries, Gustilo IIIB open tibial fracture and wound dehiscence in the distal third leg when other local reconstructive procedures are not possible. The favorable results reported in the literature, as well as the results of our work for lower limb reconstruction, are encouraging and showed good functional gain following this technique.

\section{Acknowledgements:}

This research was carried out without funding.

\section{Conflicts of interest:}

No conflicts of interest declared.

\section{Authors' contributions:}

All authors had equal role in design, work, statistical analysis and manuscript writing. All authors have approved the final article work.

\section{References}

1- AHMAD I., AKHTAR S., RASHIDI E. and KHURRAM M.F.: Hemisoleus muscle flap in the reconstruction of exposed bones in the lower limb. J. Wound Care, 22: 63542, 2013.

2- WEI F.C. and MARDINI S.: Section 2 Conventional workhorse flaps. Chapter 31, Soleus flap. Flaps and reconstructive surgery (Elsevier Inc.) pp. 422-37, 2009.

3- MORAN S. and WILLIAM P.: Cooney III Chapter 28: The Pedicled Soleus Muscle Flap for Coverage of the Middle and Distal Third of the Tibia Master Techniques in Orthopaedic Surgery: Soft Tissue Surgery (Lippincott Williams \& Wilkins) pp. 346-60, 2009.

4- FRANKEN J.M., HUPKENS P. and SPAUWEN P.H.M. The treatment of soft-tissue defects of the lower leg after a traumatic open tibial fracture Eur. J. Plast. Surg., 33: 129-33, 2010

5- KARN B.: The Use of Gastrocnemius Muscle Flap in Reconstruction of Pretibial Defects J. Nepalgunj. Med. Coll., 12: 2-5, 2014.

6- SHOEIB M.A.: Cross-Leg Flap: Its Reliability and Outcome Mod. Plast. Surg., 3: 9-14, 2013.

7- PAN H., ZHENG Q. and YANG S.: Utility of Proximally Based Sural Fasciocutaneous Flap for Knee and Proximal Lower Leg Defects WOUNDS®, 26: 132-8, 2014.

8- SCHIERLE C.F., RAWLANI V., GALIANO R.D., KIM J.Y.S. and DUMANIAN G.: A Improving outcomes of the distally based hemisoleus flap: Principles of angiosomes in flap design. Plast. Reconstr. Surg., 123: 174854, 2009.

9- KAMATH J.B.: Soft tissue coverage in open fractures of tibia. Indian J. Orthop., 46: 462-9, 2012. 
10- FILHO S.V. and FS M.V.P.: Reversed hemisoleus flap for wound coverage in the distal third of the leg (Brazilian J. Plast. Surgery), 26: 710-3, 2011.

11-PU L.L.Q.: The laterally extended medial hemisoleus flap for reconstruction of a tibial wound in the distal third of the leg Eur. J. Plast. Surg., 30: 19-24, 2007.

12- KAUFFMAN C.A., LAHODA L.U., CEDERNA P.S. and KUZON W.M.: Use of soleus muscle flaps for coverage of distal third tibial defects J. Reconstr. Microsurg., 20: 593-7, 2004.

13- TOBIN G.: Hemisoleus and reversed hemisoleus flap Plast. Reconstr. Surg., 76: 87-96, 1985.

14- PU L.L.Q.: The Reversed Medial Hemisoleus Muscle Flap and its Role in Reconstruction of an Open Tibial Wound in the Lower Third of the Leg Ann. Plast. Surg., 56: 59-64, 2006.

15- PU L.L.Q.: Successful soft-tissue coverage of a tibial wound in the distal third of the leg with a medial hemisoleus muscle flap. Plast. Reconstr. Surg., 115: 245-51, 2005.

16- RABBANI M.J., ATA-UL-HAQ, RIAZ A. and TARAR M.N.: Distally Based Medial Hemisoleus Flap: Reliable Option for Distal Tibial Wounds J. Coll. Physicians Surg. Pakistan, 28: 129-32, 2018.

17-FAYMAN M.S., ORAK F., HUGO B. and BERSON S.D.: The distally based split soleus muscle flap. Br. J. Plast. Surg., 40 20-6, 1987.

18- SAYED A.T.: Distally based medial hemi-soleus muscle flap based on the posterior tibial vessels Al-Azhar Assiut Med. J., 7: 337-53, 2009.

19- HOUDEK M.T., WAGNER E.R., WYLES C.C., SEMS S.A. and MORAN S.L.: 2016 Reverse Medial Hemisoleus Flaps for Coverage of Distal Third Leg Wounds: A Technical Trick J. Orthop. Trauma., 30: 138-42, 2009.

20- CAMPBELL K.A. and MERCURI J.J.: Updates in the management of orthopedic soft-tissue injuries associated with lower extremity trauma. Am. J. Orthop., 2014.
21- ASLAN A., UYSAL E. and ÖZMERIÇ A.: A Staged Surgical Treatment Outcome of Type 3 Open Tibial Fractures. Int. Sch. Res. Not. Orthop., 1-7, 2014.

22- ZHEN P., HU Y.Y., LUO Z.J, LIU X.Y., LU H. and Li X. S.: One-stage treatment and reconstruction of gustilo type III open tibial shaft fractures with a vascularized fibular osteoseptocutaneous flap graft. J. Orthop. Trauma, 24: 745-51, 2010

23- HELLER L.L.L.: Lower extremity microsurgical reconstruction. Plast. Reconstr. Surg., 108: 1029-41, 2001.

24- D'ALLEYRAND J., MANSON T., DANCY L., CASTILLO R.C., BERTUMEN B., MESKEY T. and O'TOOLE R.: Is time to Flap Coverage of Open Tibial Fractures an Independent Predictor of Flap-Related Complications? J. Orthop. Trauma, 28: 288-93, 2014.

25- KARBALAEIKHANI A., SAIED A. and HESHMATI A.: Effectiveness of the Gastrocsoleous flap for coverage of soft tissue defects in leg with emphasis on the distal third Arch. BONE. Jt. Surg., 3: 1-6, 2015.

26- HAMDI M.F., KALTI O. and KHELI A.: The Journal of Foot \& Ankle Surgery Experience with the Distally Based Sural Flap: A Review of 25 Cases J. Foot Ankle Surg., 51: 627-31, 2012.

27- IGNATIADIS I.A., TSIAMPA V.A., GALANAKOS S.P. GEORGAKOPOULOS G.D., GEROSTATHOPOULOS N.E., IONAC M., JIGA L.P. and POLYZOIS V.D.: The reverse sural fasciocutaneous flap for the treatment of traumatic, infectious or diabetic foot and ankle wounds: A retrospective review of 16 patients Diabet. Foot Ankle, 1: 1-7, 2011.

28- AHMAD I., AKHTAR S., KHURRAM M.F., CHOUDHARY R. and KHAN A.H.: Distally based posterior tibial artery perforator flap for coverage of defects around the ankle, heel and lower third of leg. Eur. J. Plast. Surg., 37: 547-54, 2014

29- NAZERALI R.S. and PU L.L.Q.: Free tissue transfer to the lower extremity: A paradigm shift in flap selection for soft tissue reconstruction. Ann. Plast. Surg., 70: 41922, 2013.

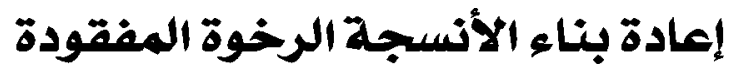 نتيجة للصدمات الثلث السفلى من الساء الرحوة العفودة}

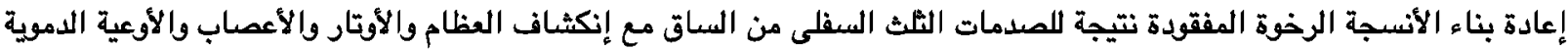

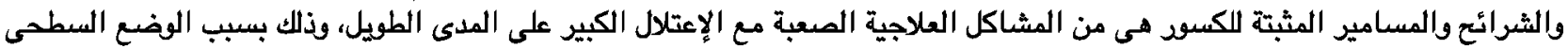

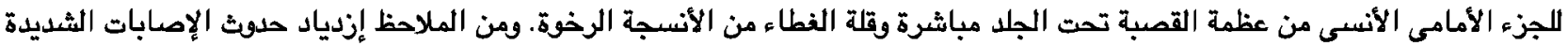

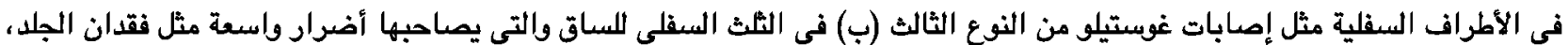

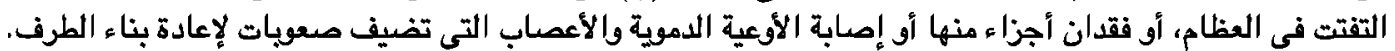

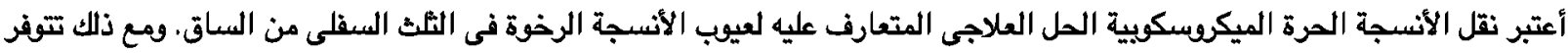

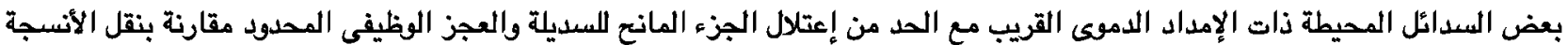

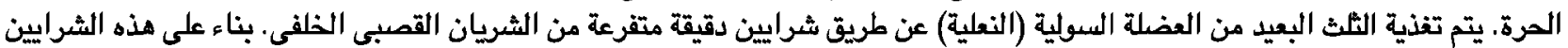

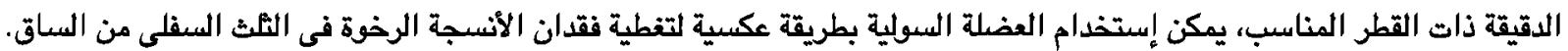

